\title{
DEPRESSION AND DEMENTIA OF CEREBROVASCULAR ORIGIN
}

\author{
Paulo Germano Marmorato, Ricardo Alberto Moreno, Silvia Belk Keila and \\ Doris Hupfeld Moreno
}

RHCFAP/3065

MARMORATO PG et al. - Depression and dementia of cerebrovascular origin. Rev. Hosp. Clín. Fac. Med. S. Paulo 57(1): 25-30, 2002.

We report the case of a patient who presented various psychiatric syndromes at the time of evaluation - partial complex epileptic seizures, personality change, and severe depression, which eventually progressed to dementia - resulting from multiple cerebral infarctions of probable neuro-angiopathic origin, of unknown etiology. Aspects related to depression following cerebrovascular accidents, as well as how cerebrovascular accidents can result in different disorders depending on the variables, are discussed based on the data from current literature.

\section{DESCRIPTORS: Depression. Vascular dementia. Epilepsy. Personality change. Stroke.}

Cerebrovascular disorders contribute greatly to the sum of psychiatric disability, chiefly in the elderly population and mainly as a result of stroke. Depression is the most prevalent psychiatric disorder to follow stroke; the rates are between $30 \%$ and $60 \%$, depending on the population studied ${ }^{1-4}$. However, mood disorders are not recognized in many stroke patients, who remain untreated, a fact that results in a poorer outcome for the patients because of its significant impact on functional recovery and rehabilitation. Vascular accidents are the second most frequent cause of dementia, accounting for $15 \%$ to $40 \%$ of all dementia cases 5 . Depression or other mental disorder is often the first symptom in cases of dementia of vascular origin ${ }^{5}$. Although most of the studies of the psychiatric consequences of stroke have concentrated on depression, evidence suggests that other psychiatric disorders such as schizophreniform and paranoid psychosis, manic states, and personality changes are also important ${ }^{18}$, and should be considered in a complete evaluation.

\section{CASE REPORT}

J. A. C., a previously healthy $72-$ year-old retired stonemason master, began to present at the age of 66 years acute (lasting a few minutes) changes of behavior: automatic and stereotyped movements of the face and upper limbs, grimacing, purposeless walking around his bed, and stepping non-existent stairways. He had no recollection of these episodes. No medical advice was sought at that time. He was a very

From the Psychiatric Institute, Hospital das Clínicas, Faculty of Medicine, University of São Paulo. respected and fearsome man due to his seriousness, methodical habits, suspiciousness, and rigid principles of behavior and was not accustomed to showing affection towards his wife and sons. After $4 \frac{1}{2}$ years, there was a conspicuous change in his characteristic personality traits: he became insecure, persistently asking his sons for reassurance regarding the things he should do, became a spendthrift, and became sexually uninhibited. Six months later, a depressed mood, anhedonia, anxiety, ideas of worthlessness, insomnia, loss of appetite, and suicidal thinking became apparent. After psychiatric consultation, he started taking fluoxetine, $20 \mathrm{mg} / \mathrm{day}$, and clonazepam, without improvement. At that time, he had a sudden episode of paresis of his left superior limb and a lowering of level of consciousness. He was taken to the emergency room where a hemorrhagic cerebrovascular accident in the right 
parietal lobe was diagnosed. After discharge, a mild paresis remained, and there was intensification of the depression with psychotic symptoms - visual and auditory hallucinations and persecutory delusions. He also attempted suicide on several occasions. He was admitted to the in-patient ward and began treatment with mirtazapine, $45 \mathrm{mg} /$ day and, after partial remission, was discharged to outpatient follow-up. He came back after a week asking to be admitted again because of the burden he represented to his family and the fear of committing suicide. Electroconvulsive therapy was indicated, but it could not be done because of the risk of new hemorrhagic episodes. An epileptic focus at the right temporal lobe was found at electroencephalogram (frequent acute waves projecting to right anterior temporal region- $-\mathrm{F} 8$ and $\mathrm{Z} 2$, diffusing to T4), and there was remission of the fits with the use of carbamazepine, $800 \mathrm{mg} /$ day (plasma level, $9.7 \mu \mathrm{g} / \mathrm{dL}$ ). Imipramine was tried at doses up to $225 \mathrm{mg} /$ day (plasma level, $15.1 \mathrm{ng} / \mathrm{dL}$ ) because of the nonresponse to lower doses and the severity of the disorder. After 15 days, delirium took place suddenly with oscillation between somnolence and intense agitation, remarkable cognitive deficits, and visual hallucinations.

Magnetic resonance showed recent frontal hemorrhage at the left frontal lobe, as well as multiple subacute and chronic lesions widespread throughout the white matter (Fig. 1). The SPECT scans (Figs. 2 and 3) showed focal hypoperfusion of the right temporal and left frontal lobes, which is evidence of functional damage.

Delirium cleared after 1 week of taking risperidone, $2 \mathrm{mg} /$ day, but psychotic depression persisted. In consideration of the fact that the anticholinergic effects of imipramine could be contributing to the delirium, treatment was changed to sertraline, up to 300 $\mathrm{mg} /$ day, combined with nortriptyline,



Figure 1 - Nuclear Magnetic Resonance - frontal hemorrhage at the left frontal lobe as well as multiple subacute and chronic lesions widespread through the white matter.

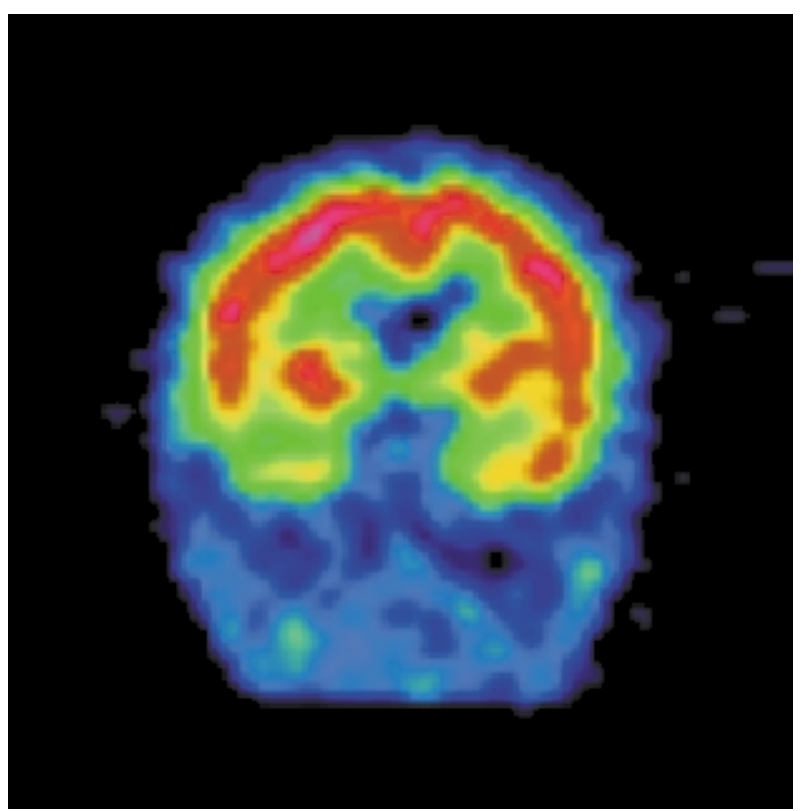

Figure 2 - SPECT scan - coronal section - right temporal hypoperfusion.

up to $100 \mathrm{mg} / \mathrm{day}$, with the result of a subsequent remission of the depressive symptoms. The combination of sertraline and nortriptyline was justified because of the linear pharmacokinetics of sertraline ${ }^{23}$, the resistant depression, and the better tolerability to side effects by the patient. Important deficits persisted in the cognitive areas of attention, memory, calculation, abstraction, and praxis, as did the slowing of psychomotor activity. There was evolution to a severe dementia with symptoms of frontal lobe syndrome, such as thought perseveration, emotional incontinence, and lack of initiative, planning, and insight.

Since image patterns in magnetic resonance and cerebral angiography suggested the presence of some kind of 


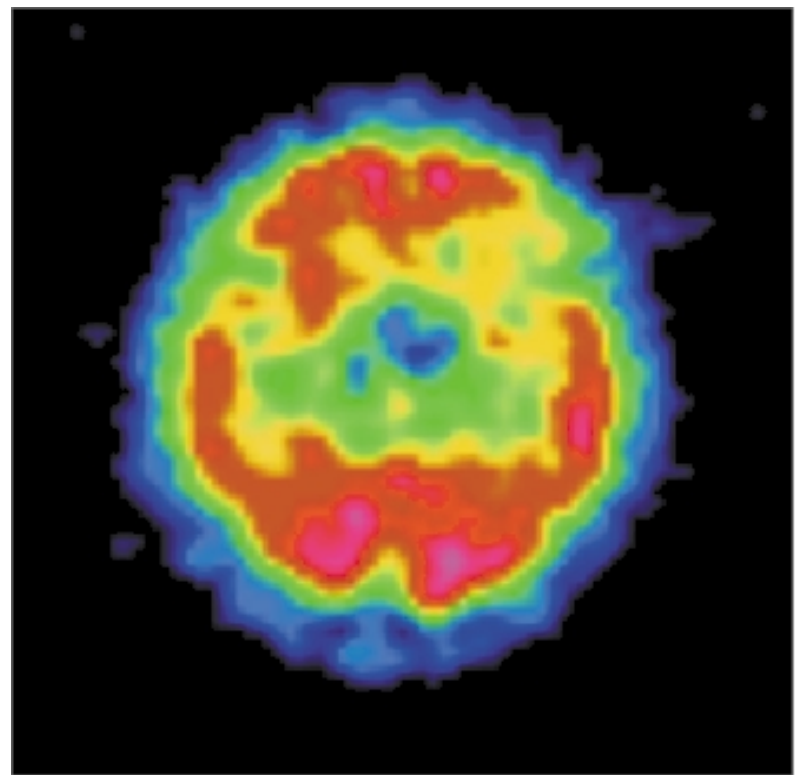

Figure 3 - SPECT scan - transversal section - left frontal hypoperfusion.

neuro-angiopathy, possibly the result of vasculitis, an investigation into the etiology based on inflammatory function tests, liquor, and cerebral biopsy was carried out, but results were inconclusive.

\section{DISCUSSION}

Magnetic resonance showed multiple subcortical hemorrhagic small lesions of the whole brain, such as in the frontal and temporal lobes, subacute and chronic, that indicate the occurrence of ischemic lesions over the course of the past few years and months. This fact seems to have contributed to the progressive psychopathological manifestations, initially expressed by a focal and intermittent manifestation, progressing to a personality change, then to psychotic depression, and eventually to a severe dementia.

The first reported mental change occurred 6 years before admission as partial complex seizures. Such epilepsy of late onset was possibly the manifestation of an ischemic lesion of the right temporal lobe, a fact that can be inferred by the ancient lesion found in this region. Epileptic phenomena, especially those of temporal lobe epilepsy, are clear examples of acute psychological disturbances that result from focal brain dysfunction, as are some of the disturbances seen after small acute cerebrovascular accidents ${ }^{5}$.

After four years, a gross change in the patient's personality traits occurred. Behavioral tendencies that had previously been enduring characteristics of the individual were altered. Brain damage often results in changes of temperament, or changed patterns of reaction to events and to other people, as well as a difficulty in adjusting to new circumstances. Such personality changes of organic origin have been attributed to widespread vascular alterations within the damaged brain and usually predict a progressive dementing illness 5 .

A depressive disorder of progressive severity with many similarities to major functional depression took place after 6 months of personality change. Since there was evidence of cerebral damage that could be assumed as the etiology for that syndrome, the diagnosis was organic depressive disorder (F06.32), according to the ICD- $10^{6}$.
The previous history raises the hypothesis of a possible dysthymic disorder and/or a personality with remarkable anancastic traits. Previous affective disorders have been found to be important risk factors for developing post-stroke depression ${ }^{7}$. Due to the paucity of reliable data, since the patient lived most of his life apart from his family, there are difficulties in clarifying this issue.

Some studies have shown that poststoke depression cannot be attributed just to a psychological reaction to physical and social disability ${ }^{8}$. The present case illustrates this fact, since depression was initiated before development of a paresis that imposed little functional impairment. Several studies suggest that left frontal lobe lesions are more frequently associated with further course of depression, even in the presence of bilateral injury, and a significant correlation has been found between severity of depression and proximity of the lesion to the frontal pole ${ }^{8-}$ ${ }^{11}$. However, a recent systematic review showed no evidence of a relationship between lesion location and depression after stroke, so this hypothesis remains a subject of controversy ${ }^{3,22}$. Lesions in this case report showed this pattern of distribution. Depression secondary to lesions in the left frontal lobe would be associated with greater severity in comparison with that caused by lesions in other areas ${ }^{12}$, as would be a predominantly dysphoric mood, anxiety, insomnia, poorer memory performance ${ }^{13}$, and pathologic emotionalism ${ }^{14}$. Subcortical atrophy was another finding present in this case that has been associated with higher incidence of depression and its clinical variability ${ }^{7,19}$.

In the present case, the damage to the frontal lobe was shown in its morphological (MRI findings) and functional (SPECT scan findings) aspects. Although stroke episodes may be associated with the postural hypotension as a side effect of imipramine, this 
should not be related to the frontal lobe stroke that happened during in-patient treatment, since postural hypotension is associated with ischemic, not hemorrhagic strokes. It has been suggested that post-stroke depression may be the consequence of severe depletions of norepinephrine and/or serotonin produced by frontal or basal ganglia lesions $^{18}$.

The depressive disorder was complicated by delusions and hallucinations that added additional distress to the patient. Some authors have associated lesions in the right hemisphere, especially in temporo-parieto-occipital areas, as well as subcortical atrophy, with risk factors for further manifestation of psychosis ${ }^{16,17}$.

Such findings support the suggestion that neurophysiological (mainly caused by damage to frontal/subcortical brain circuitry ${ }^{22}$ ) processes may play an important role-together with other variables such as social support and pre-existing personal characteristics - in the etiology of post-stroke depression.

A vascular pattern of dementia was found in the present case: cognitive losses progressing in a step-like fashion, initial manifestation of emotional changes, and fluctuation of level of consciousness after hemorrhagic episodes. The dementia syndrome consists of a constellation of symptoms that suggests widespread brain dysfunction. Some forms of dementia are best regarded as the end result of multiple focal pathologies that coalesce and combine to impair functions globally, as in the vascular dementias 5 . The pattern of lesions in the white matter for the vascular pattern is different from that of hypertensive origin, in which there are preponderant lesions of the basal ganglia, which were spared in the present case. The incidence of predominantly subcortical little lesions associated with perforating arteries found at cerebral arteriography strongly suggests a neuro-angiopathy that would cause a major susceptibility to bleeding. A cause for the neuro-angiopathy was searched for through inflammatory activity exams and cerebral biopsy. The fact that no significant changes were found does not rule out the hypothesis of some kind of vasculitis as the etiology.

Two important functional changes were seen at the SPECT scan: focal hypoperfusion of right temporal and left frontal lobes. Changes in these cerebral regions are shown in the literature to be related to memory deficits, personality changes, depressive symptoms, and frontal lobe syndrome ${ }^{17,18}$ —all clinical changes that were presented by the patient along the course of his illness.

Concerning treatment, the use of nortriptyline was found to produce better results than the placebo in one of the few post-stroke depression treatment studies performed ${ }^{20,23}$. Treatment with nortriptyline had a significant effect, but complete remission of depressive symptoms was not achieved. This result is not surprising, since widespread lesions and the consequent overall brain dysfunction have been suggested to be associated with poor remission of symptoms ${ }^{1}$.

This case illustrates the various psychopathological manifestations caused by progressive damage to the brain. In 6 years, more severe symp- toms were added to preexisting ones that eventually culminated in severe dementia. Inferences can be made relating specific symptoms and syndromes to dysfunctions in localized brain areas that agree with data reported in the literature. However, many of these studies need to be replicated. Since the relationships between brain damage and mental symptoms are quite complex, other possible etiological factors such as disability, lesion size, cognitive impairment, and social functioning should be taken into account $^{18,22}$.

The clinician ought to remain aware that occasionally mental illness presenting as personality change, affective disturbance, and psychotic symptoms may be related to the early stages of cerebral disease and that such cases are not unusual, especially in elderly patients. The importance of recognizing post-stroke depression should be emphasized because of its high prevalence and because when it is not correctly diagnosed and effectively treated, the course of disease will worsen due to lack of cooperation with rehabilitation and the deficiencies caused by the stroke. The study of such patients provides us with the opportunity not only to examine those factors that produce psychiatric disorder but also factors that exert protective effects against it or that cannot ameliorate this disorder.

\section{ACKNOWLEDGEMENT}

The authors would like to thank the kind contribution of Ms Flávia Barata for the revision of the English text. 
MARMORATO PG e col. - Depressão e demência de origem cerebrovascular. Rev. Hosp. Clín. Fac. Med. S. Paulo 57(1):25-30, 2002.

Relatamos o caso de um paciente que apresentou diversas síndromes psiquiátricas ao longo do tempo - crises epilépticas parciais complexas, altera- ção de personalidade e depressão grave que finalmente progrediu para demência - resultantes de múltiplos infartos cerebrais de provável origem neuroangiopática cuja etiologia permaneceu indeterminada. São discutidos aspectos relacionados a depressões secundárias a acidentes cerebrovasculares, assim como estes podem resul- tar em diferentes transtornos de acordo com algumas variáveis que são discutidas com base nos dados da literatura atual.

DESCRITORES: Depressão. Demência vascular. Epilepsia. Alteração de personalidade. Acidente vascular cerebral.

\section{REFERENCES}

1. STARKSTEIN ES, ROBINSON RG \& PRICE TR - Comparison of recovered versus nonrecovered patients with poststroke depression. Stroke 1988;19:1491-1496.

2. ROBINSON RG, MORRIS PL \& FEDOROF JP - Depression and cerebrovascular disease. J Clin Psychiatry 1990; 51(suppl. July): 26-31.

3. PRIMEAU F - Post-stroke depression: A critical review of the literature. Can J Psychiatry 1998; 33(8):757-764.

4. OPPENHEIMER S \& HACHINSKI V - Complications of acute stroke. Lancet 1992; 339:721-724.

5. LISHMAN WA - Organic Psychiatry. $3^{\text {th }}$ ed. Oxford, Blackwell Science, 1998

6. OMS - Classificação de transtornos mentais e de comportamento da CID-10. S. Paulo, Artes Médicas, 1993.

7. ANDERSEN G, VESTERGAARD K, INGEMANN-NIELSEN M et al. - Risk factors for post-stroke depression. Acta Psychiatrica Scand 1995; 92:193-198.
8. ROBINSON RG, KUBOS KL, STARR LB et al. - Mood disorders in stroke patients: importance of location of lesion. Brain 1984; 107,81-93.

9. LIPSEY JR, ROBINSON RG, PEARLSON GD et al. - Mood change following bilateral brain injury. Brit J Psychiatry 1983; 143:266273.

10.EASTWOOD MR, RIFAT SL, NOBBS $\mathrm{H}$ et al. - Mood disorder following cerebrovascular accident. Brit J Psychiatry 1989; 154:195-200.

11. CARSON JA, MACHALE K, ALLEN K et al. - Depression after stroke and lesion location: a systematic review. Lancet 2000; 356:122-126.

12. BOLLA-WILSON K, ROBINSON RG, STARKSTEIN SE, et al. Lateralization of dementia of depression in stroke patients. Am J Psychiatry 1989; 146:627-634.

13. STERN AR \& BACHMAN DL - Depressive symptoms following stroke. Am J Psychiatry 1991; 148:351-356. 
14. HOUSE A, DENNIS M, MOLINEUX A et al. - Emotionalism after stroke. Br Med J 1989; 298:991-994.

15. RABINS PV, STARKSTEIN SE \& ROBINSON RG - Risk factors for developing atypical (schizophreniform) psychosis following stroke. J Neuropsychiatry Clin Neurosci 1991; 3:6-9.

16. LEVINE DN \& FINKLESTEIN S - Delayed psychosis after right temporo-parietal stroke or trauma: relation to epilepsy. Neurology 1982; 32:267-273.

17. ROBINSON RG \& STARKSTEIN SE - Neuropsychiatric aspects of cerebrovascular disorders. In: SADOCK BJ \& SADOCK VA Comprehensive Textbook of Psychiatry. $7^{\text {the }}$. Philadelphia, Lippincott, 2000,

18. BARBER R, SHELTENS P, GHOLKAR A et al. - White matter lesions on magnetic resonance imaging in dementia with Lewy bodies, Alzheimer's disease, vascular dementia and normal aging. J Neurol Neurosurg Psychiatry 1999;67:66-72.
19. LIPSEY JR, ROBINSON RG, PEARLSON GD et al. - Nortriptyline treatment of post-stroke depression: a double blind study. Lancet 1984; 1:297.

20. JOHNSON GA - Research into psychiatric disorder after stroke: the need for further studies. Aust N Z J Psychiatry 1991; 25:358-370.

21. RAO R - Cerebrovascular disease and late life depression: an age old association revisited. Int J Geriatric Psychiatry 2000; 15,419 433

22. KIMURA M, ROBINSON RG \& KOSIER JT - Treatment of cognitive impairment after post-stroke depression: a double-blind treatment trial. Stroke 2000; 31:1482-1486.

23. THE UNITED STATES Pharmacopeial Dispensing Information. Sertralina systemic. In: Drug Information for the Health Care Professional. USP-DI, Massachusetts, Micromedex, 2000. p. 25662570.

Received for publication on January 23, 2001. 